\title{
Compare the Similarities and Differences between the Higher Education Accreditation Standards in Vietnam and QMS ISO 9001:2008
}

\author{
Vu-Hoang Le \\ Testing and Quality Assurance Department, Ho Chi Minh City University of Food Industry, Vietnam
}

Copyright@2017 by authors, all rights reserved. Authors agree that this article remains permanently open access under the terms of the Creative Commons Attribution License 4.0 International License

\begin{abstract}
The trend of globalization and international integration poses many challenges for tertiary education in Vietnam. Quality education is a matter of social concern and the most competitive in the training occurs with increasing drastic levels. On that basis, a number of Universities are trying to improve the quality of education and training in Vietnam. Currently, many Universities in Vietnam select the method of Quality Management according to QMS ISO 9001: 2008, a registration accreditation under the accreditation standards of Education \& Training. Therefore, the quality management according to QMS ISO 9001: 2008 registration and accreditation has nothing alike and different. Regulatory role of Universities leadership and involvement of all leaders, teachers, and staff in quality assurance within the University are shown how to meet the needs of customers increasingly better than.
\end{abstract}

Keywords Quality Systems, Accreditation of Education and Training, Quality Higher Education

\section{Introduction}

\subsection{Educational Testing System Vietnam}

\subsubsection{The Purpose and Objective of Inspection}

Purpose: Evaluating quality assurance not only shows that the university is responsible for the quality of education, but also brings improved motivation and quality improvement programs for the whole universities.

Objective: Quality accreditation helps ensure and improve the quality of education and determine the degree to meet its objectives in certain stages; as a basis for accountability to the state authorities and the society on the status of education quality; as the basis for universities choice students and labor recruiters recruit manpower.

\subsubsection{Characteristic of Accreditation}

- Quality inspection may be conducted in the schools or training programs.

- Quality Accreditation is completely voluntary activity.

- Verification quality of self-assessment is inseparable.

- All testing process is always associated with rating peers.

- The assessment criteria are flexible and modified to suit the mission of universities.

- Inspection and testing universities-level program not only focuses on assessing the inputs but also on the process and quality of training of students at the university.

\subsubsection{The Role of Accreditation for Higher Education}

Help universities to review the entire operation of the universities in a systematic manner so that adjusts the universities activities in a certain benchmark. There have been many different concepts of quality and quality trainings are evaluated by the input word for that quality of a university depends on the input quality of students were enrolled in public schools that field i.e. high entrance scores are high quality. Some people have different views about the quality of higher education that "output" of higher education more important than "Input". "Output" is the product of higher education is represented by the degree of completion of work of graduates or the ability to provide training activities of schools. Quality output is mainly expressed through the learning outcomes of students in student transcripts.

Quality inspection helps universities determine the orientation and certain quality standards. According to the consolidated text number: 06/VBHN-BGDDT, dated 04 May 032014 about gauge quality university education, the school is accredited and comprehensive review of the activities of the school with ten standards. Each standard has specific criteria. These standards are the directions for the construction and development of the university in the current period with the following basic content:

Standard 1: Mission and goals of the university;

Standard 2: Organization and management;

Standard 3: Curriculum; 
Standard 4: Training activities;

Standard 5: management staff, faculty and staff;

Standard 6: The learner;

Standard 7: Scientific research, application, development and technology transfer;

Standard 8: Activities of international cooperation;

Standard 9: Library, learning equipment and other facilities; Standard 10: Finance and Financial Management.

Evaluating quality assurance mechanisms to create quality flexible medium, tight fit. Quality assurance mechanisms include self-assessment and external assessment. The result of each process is the self-assessment reports and external assessment report. To implement this mechanism, each university should develop systems of internal quality assurance (Internal Quality Assurance - the IQA) and Ministry of Education and Training, the independent accreditation organizations and institutions other socio-professional perform external quality assurance (external quality assurance - EQA). Between internal quality assurance and external quality assurance is always feedback of every activity, every process.

Through practice the Bureau figures Testing \& Quality Accreditation updated on 11/31/2013 education universities, institutes (168) completed a self-assessment report. The self-evaluation report of the reported cases is very complete, detailed and specific about the current status of universities quality. The report pointed out the strengths, constraints and the perfect direction, consolidating and improving the quality of schools. Many managers have confirmed, if compared to the annual report that the school setting, the self-assessment report is the most comprehensive report, most system. Another point worth noting is that in the process of accreditation, as criticism has been focused. After the self-assessment report was completed, the school is evaluated in addition.

Under current regulations, the external evaluation by professionals knowledgeable about the quality of the expertise and experience in managing is ongoing. The external assessment is an objective view of the quality of universities. The external evaluation has just critical self-evaluation report of the school, ensuring the interests of society, employers and students - those objects that are usually called client of the school. This activity contributes to solving a problem exists today as the university has always claimed their quality of higher education, thereby meeting the demands of society.

In order to solve this problem needs through third parties through an objective evaluation from outside - an element of accreditation. External assessment helps university recognize the quality of our current and announced to customers on the current state of the quality of university.

\subsection{The Basic Contents of QMS ISO 9001: 2008 Applies a Quality Management in Education and Training}

Here are the main provisions required to implement and must be tightly controlled in the process of applying QMS ISO 9001: 2008.

Table 1. The main provisions of ISO 9001: 2008

\begin{tabular}{|c|c|}
\hline ISO 9001:2008 & Terms, request \\
\hline Quality management system & $\begin{array}{c}4 \\
(4.1 ; 4.2)\end{array}$ \\
\hline Leadership responsibilities & 5 \\
\hline Resource management & $(5.1 ; 5.2 ; 5.3 ; 5.4 ; 5.5 ; 5.6)$ \\
\hline Implement Production & $\begin{array}{c}6 \\
\text { Measurement, analysis and } \\
\text { improvement }\end{array}$ \\
\hline
\end{tabular}

The model of quality management system according to ISO 9001: 2008 contains five terms, each provision is presented in the form of a model quality management system based on the amounts of 1 approach the process (Input $\rightarrow$ process $\rightarrow$ output).

\section{The Method Used to Assess and Manage the Quality of Education and Training}

\subsection{ISO 9001: 2008}

Assessment methods based on the description and justification of the terms applied under the system based on the functions and tasks of the units of the organization are as follows: consider the implementation of quality objectives and implementation plan quality objectives have been registered and approved; powers, responsibilities and job descriptions; process procedures / work instructions and regulations related to the management and service training; measurement results of customer satisfaction and customer internal outside; Results resolve the customer's requirements; The rules and procedures listed publicly conducted.

\subsection{By the Standards of Accreditation}

For the accreditation of training in self-evaluation process (internal quality assurance) according to the norms of standards / criteria (10 standards and 61 criteria) on inspection of the Ministry of Education \& training to conduct a review, self-assessment and report on the status of the quality and effectiveness of training activities, scientific research. Work performed under the self-assessment method: description to clarify the status of the criteria; analyze, compare to important assumptions assessment, pointing out the strengths, point exists; plans to overcome these shortcomings and improvements to enhance the quality of education.

Quality testing provides a mechanism to ensure the quality both flexible, tight fit. Quality assurance mechanisms include self-assessment and external assessment. The result of each process is the self-assessment reports and external assessment report. To implement this mechanism, each 
university should develop systems of internal quality assurance (Internal Quality Assurance - IQA) and Ministry of Education and Training, the independent testing organizations and institutions other social and professional implementation of external quality assurance (external quality assurance - EQA). Between internal quality assurance and external quality assurance always feedback of each action, each process.

Through the actual data has been testing \& Inspection Department of the quality of education dated 11/31/2013 update universities, institutes (168) has completed a self-assessment report. The self-assessment report of the reported cases is very complete, detailed and specific about the quality of the status quo. The report pointed out the strengths, drawbacks and the finishing direction, strengthen and improve the quality of the school. Many managers have confirmed, if compared to the annual report that the school set up the self-evaluation report is the most comprehensive report, unified system. One point worth noting is that during testing, critical properties has been focused. After the self-assessment report was completed, the school is evaluated in addition. Under current regulations, the external assessment by experts knowledgeable about the quality of the expertise and experience in the management conducted. The external assessment is an objective view of the quality of the school. The external assessment has critical self-evaluation report of the school, ensuring the interests of society, employers, and students - those objects that are often referred to as the school's clients. This activity contributes to solving existing problems at present are the universities always declared their training bochat high quality, guaranteed to meet the requirements of society, but society and employers often complaining that the current quality of education is not good, do not meet their requirements.

In order to resolve this issue through a third party needs is through an objective evaluation from the outside - a component of accreditation. External assessment helps schools recognize the quality of our current and announced to customers on the status of the quality of schools.

\subsection{Inspection Results}

As one of the criteria for stratification and ranking of higher education establishments (Provision 9 - Law on Higher Education). As a basis for determining the quality of higher education, position and prestige of higher education institutions, implementation of autonomy, self-responsibility; investment support, the task; State as a basis for social and monitor the activities of higher education institutions (Provision 53 - Law on Higher Education) [25].

\subsection{Process and Quality Inspection Cycle Education}

The process of education quality accreditation includes the following steps: educational establishments conducted a self-assessment; educational institutions registered with an external review organization accrediting education and proposed to consider recognizing standards of education quality; accrediting organizations conducting education external assessment; organizing educational accreditation evaluation, recognized or not recognized educational institutions achieve educational quality standards. Education quality testing is done every 5 years / times.

\section{Comparison of the ISO 9001: 2008 with the Accreditation Standards of the Ministry of Education and Training}

\subsection{The Difference between Accreditation Standards and ISO 9001: 2008}

Table 2. The difference between accreditation standards and ISO 9001: 2008

\begin{tabular}{|c|c|c|}
\hline $\mathrm{N}^{0}$ & $\begin{array}{c}\text { Standards / criteria of } \\
\text { accreditation }\end{array}$ & $\begin{array}{c}\text { Terms, requirements of ISO } \\
9001: 2008\end{array}$ \\
\hline \multicolumn{3}{|c|}{ Standard 2: Organization and Management } \\
\hline 1 & 2.4 & No \\
\hline \multicolumn{3}{|c|}{ Standard 5: management staff, faculty and staff } \\
\hline 2 & 5.3 & No \\
\hline 3 & 5.5 & n/a \\
\hline 4 & 5.7 & n/a \\
\hline \multicolumn{3}{|c|}{ Standard 6: The Students } \\
\hline 5 & 6.4 & n/a \\
\hline 6 & 6.6 & n/a \\
\hline Standard 7: Scientific research, application, development and \\
\hline \multicolumn{3}{|c|}{ technology transfer } \\
\hline 7 & 7.5 & n/a \\
\hline 8 & 7.7 & n/a \\
\hline \multicolumn{2}{|c|}{ Standard 9: Library, learning equipment and other facilities } \\
\hline 9 & 9.2 & \\
\hline 10 & 9.7 &
\end{tabular}

Do peculiar political system, education and culture should be the Ministry of testing standards MOET of Vietnam has unique features compared to the standard ISO 9001: 2008 is widely used in 187 countries worldwide is considered. According to the content of the standards, criteria 2.4, 5.3, 5.5, 5.7, 6.4, 6.6, 7.5, 7.7, 9.2, 9.7 are driven by goals and direction of the school and all activities must comply according to the general regulations of education by the competent authority issued, and must submit to the management and execution of guidelines and policies of the Party, State and local governments and agencies Administration of education at all levels. ISO 9001: 2008 is widely used in many areas such as public administration, in production, in education ... Thus, the provisions applicable in ISO 9001: 2008 is mainly qualitative (the process of implementation), describe specific contents but not specified the amount of detail. Meanwhile, the criteria of the accreditation criteria of the Ministry of Education and Training give detailed requirements on these indicators to specific quantitative. 


\subsection{Similarities between Accreditation and ISO 9001: 2008}

Table 3. Similarities between the accrediting criteria and ISO

\begin{tabular}{|c|c|c|}
\hline $\mathrm{N}^{0}$ & Standards / criteria of accreditation & Terms, requirements of ISO 9001: 2008 \\
\hline \multicolumn{3}{|c|}{ Standard 1: Mission and goals of the university } \\
\hline 1 & 1.1 & 5.3 \\
\hline 2 & 1.2 & 5.4.1 \\
\hline \multicolumn{3}{|c|}{ Standard 2: Organization and Management } \\
\hline 3 & 2.1 & 4.1 \\
\hline 4 & 2.2 & 4.2 .3 \\
\hline 5 & 2.3 & 5.5 .1 \\
\hline 6 & 2.5 & 5.4 .2 \\
\hline 7 & 2.6 & 5.4.1, 5.4.2, 8.2.2 \\
\hline 8 & 2.7 & $4.2 .3,4.2 .4$ \\
\hline \multicolumn{3}{|c|}{ Standard 3: Curriculum } \\
\hline 9 & 3.1 & 7.3.1 \\
\hline 10 & 3.2 & 7.3 .2 \\
\hline 11 & 3.3 & 7.3.3 \\
\hline 12 & 3.4 & 7.3.4 \\
\hline 13 & 3.5 & 7.4 .1 \\
\hline 14 & 3.6 & 7.3.7 \\
\hline 15 & 3.7 & 8.2 .1 \\
\hline \multicolumn{3}{|c|}{ Standard 4: Training activities } \\
\hline 16 & 4.1 & 8.2 .1 \\
\hline 17 & 4.2 & 7.5 .1 \\
\hline 18 & 4.3 & 7.5.1 \\
\hline 19 & 4.4 & 8.2 .4 \\
\hline 20 & 4.5 & 7.2.4 \\
\hline 21 & 4.6 & 8.2 .1 \\
\hline 22 & 4.7 & 8.2 .3 \\
\hline \multicolumn{3}{|c|}{ Standard 5: Management staff, faculty and staff; standard } \\
\hline 23 & 5.1 & 7.4 .3 \\
\hline 24 & 5.2 & 8.2 .2 \\
\hline 25 & 5.4 & 8.2 .2 \\
\hline 26 & 5.6 & 5.4 .1 \\
\hline \multicolumn{3}{|c|}{ Standard 6: The learner } \\
\hline 27 & 6.1 & 7.2 .3 \\
\hline 28 & 6.2 & 6.2 \\
\hline 29 & 6.3 & 8.2 .4 \\
\hline 30 & 6.5 & 7.2 .3 \\
\hline 31 & 6.7 & 7.2 \\
\hline 32 & 6.8 & 8.2 .4 \\
\hline 33 & 6.9 & 8.2 .4 \\
\hline \multicolumn{3}{|c|}{ Standard 7: Scientific research, application, development and technology transfer } \\
\hline 34 & 7.1 & 7.3.4 \\
\hline 35 & 7.2 & 7.3 \\
\hline 36 & 7.3 & 7.3 \\
\hline 37 & 7.4 & 7.3 \\
\hline 38 & 7.6 & 7.3 \\
\hline \multicolumn{3}{|c|}{ Standard 8: International Cooperation Activities } \\
\hline 39 & 8.1 & 7.5 .1 \\
\hline
\end{tabular}




\begin{tabular}{|c|c|c|}
\hline 40 & 8.2 & 7.5 .1 \\
\hline 41 & 8.3 & 7.3 \\
\hline \multicolumn{3}{|c|}{ Standard 9: Library, learning equipment and other facilities } \\
\hline 42 & 9.1 & 7.5 .1 \\
\hline 43 & 9.3 & 6.3 \\
\hline 44 & 9.4 & 6.3 \\
\hline 45 & 9.5 & 6.3 \\
\hline 46 & 9.6 & 6.3 \\
\hline 47 & 9.8 & 6.2 .4 \\
\hline 48 & 9.9 & 5.4 .2 \\
\hline \multicolumn{2}{|c|}{ Standard 10: Finance and Financial Management } \\
\hline 49 & 10.1 & 7.5 .1 \\
\hline 50 & 10.2 & 6.4 \\
\hline 51 & 10.3 & 6.4 \\
\hline
\end{tabular}

ISO 9001: 2008 with the accreditation criteria of The Ministry of Education and Training has many provisions respond quite full and detailed (process control procedures implemented by the process) according to the theory of calibration standards, considering most of the areas, aspects of school operations. Therefore, the application of quality management system ISO 9001: 2008 will result in steady and high reliability in the preparation of documents for proof testing standards.

ISO 9001: 2008 a majority of the terms applied to focus on the management and implementation process, the commitment of the leaders of the unit should be consistent with quality management and better service for inspection quality education and training. ISO 9001: 2008 is applied at the University of Food Industry in Ho Chi Minh City to meet criteria $51 / 61$ proportion $83.61 \%$ of the accreditation criteria of the Ministry of Education and Training, 51 response criteria application most important content testing standards such as: (mission, objectives, managers, trainers, teaching activities, learning environment, educational outcomes, and facilities). Based on the evaluation methodology of ISO 9001: 2008 quality accreditation standards all records testament to ISO 9001: 2008 which fully meet requirements of the 51 criteria for accreditation and assessment that meets the requirements of accreditation criteria

\section{Solutions Built the Universities Quality Management}

\subsection{Solution Associated to Standards / Criteria for Accreditation of Higher Education in the Education \& Training}

The ISO 9001: 2008 also achieved a certain value when put into management and quality control in higher education. Due to the peculiar political system, education and culture should be the Ministry of testing standards MOET of Vietnam has unique features compared to the standard ISO 9001: 2008 is widely used in 187 countries worldwide be considered. According to the content of the standards, criteria 2.4, 5.3, 5.5, 5.7, 6.4, 6.6, 7.5, 7.7, 9.2, 9.7 are driven by goals and direction of the school and all activities must comply according to the general regulations of education by the competent authorities issued, and must submit to the management and implementation of the guidelines and policies of the Party, State and local governments and agencies educational administration at all levels. ISO 9001: 2008 is widely used in many areas such as public administration, in production, in education ... Thus, the provisions applicable in the standard ISO 9001: 2008 is mainly qualitative (the process of implementation), describe the specific content, but does not specify the amount of detail. Meanwhile, the criteria of the accreditation standards of the Ministry of Education and Training give detailed requirements on these metrics with specific quantitative results. Therefore, when applying this standard in schools should be based on implementation resources and the strong commitment from the leadership of the school to be able to meet the requirements set forth in the exchange situation powerful new in higher education and to the highest quality instruction.

This is the scientific basis to propose solutions necessary and feasible to supplement the requirements of the 10 criteria lacking in developing quality management at the University of Food Industry of HCMC to ensure the quality of training, uniform in structure and satisfactory customer's internal and external customers and the missing criteria were:

Criterion 2.4: Party organizations and mass organizations in universities operate efficiently and are rated good in the annual rating; activities in schools adhere to the principle of democratic centralism;

Criterion 5.3: policies and measures to facilitate management staff and faculty to participate in professional activities, operations at home and abroad;

Criteria 5.5: Is there a sufficient number of teachers to implement educational programs and scientific research; achieve the goal of education development strategy to reduce the average student / faculty 
Criterion 5.7: Faculty guaranteed balance of professional work experience and rejuvenation of the teaching staff as prescribed;

Criterion 6.4: The Party and mass work well in the practice of politics, ideology, ethics and lifestyle for students;

Criterion 6.6: Regular propaganda, moral education, healthy lifestyle, sense of responsibility, respect for law, policy, guidelines and policies of the Party and State, and the school's rules for learner;

Criterion 7.5: Ensure revenue from scientific research and technology transfer not less than the university budget for these activities;

Criterion 7.7: There are specific regulations on standards of competence and ethics in scientific activities and technology as prescribed; take measures to ensure intellectual property rights;

Criteria 9.2: Is there a sufficient number of classrooms, a large lecture hall, practice rooms, laboratory service of teaching, learning and scientific research to meet the requirements of each industry training;

Criterion 9.7: There is enough area of land use under the provisions of TCVN 3981-85. The overall surface area is at least as prescribed.

\subsection{Construction Activity Improved Quality Management System}

In recent years, the University has made but not diverse forms, largely limited to the organization of seminars preliminary and final. So to the improvement activities effectively, in the future, to consider the organization with more diverse forms. Here are specific suggestions.

To organize seminars and training to raise awareness of ISO 9000, on administrative reform for managers to create a shift in perception.

Establish a network of quality and quality improvement groups of the units for developing nuclear program. Each year to review and evaluate the achievements, shortcomings arise to propose solutions and develop a plan for next year.

To organize study tours and exchange experiences with the unit in and out of school are more successful in quality management activities at higher education level.

\subsection{These Steps Apply Quality Management System}

Table 4. Construction process of quality management system of universities

\begin{tabular}{|c|c|}
\hline Flowchart & Contents \\
\hline $\begin{array}{c}\text { Define content management } \\
\text { needs }\end{array}$ & $\begin{array}{c}\text { Determined according to } 10 \text { criteria assessing } \\
\text { the quality of education }\end{array}$ \\
\hline $\begin{array}{l}\text { Determining the structure } \\
\text { of the system }\end{array}$ & $\begin{array}{l}\text { Construction work scheme applies to } \\
\text { management under ISO 9001: } 2008\end{array}$ \\
\hline $\begin{array}{l}\text { Develop processes for each } \\
\text { content management }\end{array}$ & $\begin{array}{l}\text { Based on the quality control according to ISO } \\
\text { 9001: 2008: Inputs, the implementation process, } \\
\text { output }\end{array}$ \\
\hline $\begin{array}{l}\text { Develop evaluation criteria for } \\
\text { each content management }\end{array}$ & $\begin{array}{l}\text { Based on the policies and objectives of the } \\
\text { assessment to build specific criteria }\end{array}$ \\
\hline 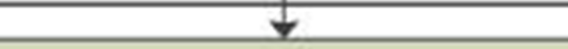 & \multirow[b]{2}{*}{$\begin{array}{c}\text { Based on eight quality management principles } \\
\text { in the of ISO } 9001: 2008\end{array}$} \\
\hline Operating system & \\
\hline Review and improve the system & $\begin{array}{c}\text { Periodically conduct internal assessment and } \\
\text { external review by criteria built according to } \\
\text { the standard }\end{array}$ \\
\hline
\end{tabular}




\section{Conclusions}

Application of ISO 9001: 2008 in the field of education and training in Vietnam is still a new problem, despite many universities have adopted from 2005 until now, but some universities that applied to pivot very little work and maintain stability, improvements to enhance the quality of the units seem to have the capacity and shortness of breath on the commitment of the leaders of the unit. Recently, Prime Minister Nguyen Tan Dung signed Decision No. 19/2014 / QD-TTg, dated 03.05. 2014 requesting the application of quality management system according to the National Standard ISO 9001: 2008 with the operation of agencies and organizations within the state administrative system. This is a favorable legal basis for schools trying to apply this management system. However, to operate the ISO 9001: 2008 really effective in higher education, we should focus on considering the following issues:

When applying ISO 9001: 2008 in higher education, many servants agency found no benefit of their own but must do a better job, a responsibility to be higher, stricter discipline. Thereby, lead to cause the shutdown of system. Therefore, the determination of the leadership is a prerequisite for successful adoption.

ISO 9001: 2008 requirements just yet to make clear, not only to make specific requests to make it how this standard should be no general model for schools. So schools have to rely on their characteristics to develop appropriate systems. Each school cannot apply model machines ISO 9001: 2008 is available that requires creativity in building the system. Similarities of the field while building a quality management system according to ISO 9001: 2008 requires a huge effort and continuity of all civil servants and employees.

On the other hand, students and employers are the direct customers of the school. Measure of administrative reform to improve quality is reflected in customer satisfaction in education and training. Therefore, the customer satisfaction survey objectively and independently also contributes to improving the quality of education of the university.

With such views, the authors offer solutions and suggestions for the application of ISO 9001: 2008 to improve the quality of the management of the University of Food Industry in Ho Chi Minh City. At the same time, prepared and ready for the registration of certificates of independent testing organizations in education under the 10 standards and 61 criteria of the Ministry of Education and Training. Besides, the application of quality management system ISO 9001: 2008 has helped change the mindset and old management habits, forming new habits of thinking and quality management training, quality management guide to satisfy the needs of customers, implement synchronous measures affecting the entire process of formation of the quality of training, clearly defined roles and responsibilities of each individual, the department throughout the school to ensure protect and improve the quality of training, performance management system according to the quality management documents, management efficiency is improved and enhanced the competitive position of the quality of education at the University of Food Industry Ho Chi Minh city with the universities in the country and the region.

\section{Acknowledgements}

This study serves to knit maze study authors about quality management in higher education level, Vietnam.

\section{REFERENCES}

[1] Ta Thi Kieu An (2010), Statistical Publishing House, Quality Management.

[2] Nguyen Duc Chinh (2002), Accreditation in Higher Education, the National Education Publishing Hanoi, Hanoi.

[3] Tran Khanh Duc (2009), education and human resources development in the XXI century, the Vietnam Education Publishing House.

[4] Nguyen Minh Dinh, Nguyen Trung Tin, Pham Phuong Hoa (1996), effective management method Deming, HCMC Statistical Publishing House.

[5] Nguyen Kim Dung (2008), Definition of terms in the field of testing and ensuring the quality of education.

[6] Nguyen Kim Dung (2009), Construction of calibration standards for the training program at the Pedagogical

[7] University, Ho Chi Minh City University of Pedagogy, HCMC.

[8] Proceedings ISO Vietnam (2002-2003), Commercial Information Center, Ministry of Commerce.

[9] Nguyen Hoi Nghia (2014), Movement ASEAN Quality Assurance, Testing Center evaluation of the quality of training, Ho Chi Minh City National University.

[10] Nguyen Van Nhon (2007), Application of ISO 9000: 2000 in the College, University, Center for International quality - IQC.

[11] Bui Duc Tai (2006), Master's thesis analysis and application solutions QMS ISO 9001: 2000 to improve the quality of management education in the College of Food Industry of HCMC, Hanoi.

[12] Tran Quang Tue 11. (2001), What is Quality Management?, City Publishing House. Ho Chi Minh.

[13] HCMC University of Food Industry (2013), Report on the application of ISO 9001: 2008.

[14] HCMC University of Food Industry (2012), Report on the academic year 2011-2012.

[15] HCMC University of Food Industry (2013), Report on the academic year 2012-2013. 
[16] HCMC University of Food Industry (2014), report on self-evaluation and quality assurance of education.

[17] HCMC University of Food Industry, innovative pilot scheme operating mechanisms period 2014-2017.

[18] HCMC University of Food Industry (2011), Handbook of Quality Management System ISO 9001: 2008.

[19] Nguyen Quang Toan (1990), Some basics of QCS, HCM City Economics University.

[20] Tran Thi Thuy (2007), master's thesis analyzes and evaluation of the accreditation application at colleges Food

[21] Industry in Ho Chi Minh City College of Food Industry of HCMC, Hanoi.

[22] Tran Protection (1997), Management of school education, science education Institute, Hanoi.

[23] International Quality Centre - IQC (2005), Application of ISO 9000: 2000 and trained internal auditors to manage higher education colleges - Copyright IQC.

[24] Joseph M. Juran's quality 22. handbook (1999), McGraw Hill.

[25] Ministry of Education and Training, Education Law (2013).
[26] Decision No 65/2007 / QD-BGDĐT, November 1, 2007 by the Minister of Education and Training issued the Regulation on the evaluation criteria of quality university education.

[27] Decision No 76/2007 / QD-BGDĐT issued 14/12/2007 cycle processes and education quality accreditation.

[28] Decision No 144/2006 / QD-TTg Hanoi, June 20, 2006 About the application of quality management system standard ISO 9001: 2000 on the operation of administrative agencies government.

[29] International Organization for Standardization ISO 9001: 2008, Quality management systems - requirements, third edition.

[30] Circular No. 62/2012 / TT-BGDĐT, December 28, 2012 by the Minister of Education and Training issued the Regulation on the procedure and accreditation cycle university education, higher professional and middle class.

[31] ISO 8402: 1999, Quality management and elements of the quality system - Base vocabulary.

[32] ISO 9000: 2005 quality-management system and vocabulary base.

[33] Consolidated Text number: 06 / VBHN-BGDĐT, dated 04 May 201403 of the Minister of Education and Training. 